\title{
DESIGN-FOR-COST-AND-ENVIRONMENT: ONTOLOGICAL ANALYSIS AND COMPARISON OF SERVICE REPRESENTATION APPROACHES
}

\author{
M. Villanueva ${ }^{1,2, \otimes}$, B. Yannou ${ }^{1}$, Y. Leroy ${ }^{1}$, F. Cluzel ${ }^{1}$, M. Vautier ${ }^{2}$ and S. Vaija ${ }^{2}$ \\ ${ }^{1}$ CentraleSupélec, France, ${ }^{2}$ Orange Labs, France \\ $\triangle$ marcel.villanueva@orange.com
}

\begin{abstract}
Brought by the need for competent approaches to assess the financial cost and environmental impact towards service design-for-cost-and-environment, this paper investigates on the following service representation approaches: Service Blueprinting, Process Chain Network, Business Process Model \& Notation, and Customer Journey Mapping. An ontological analysis further compares their similarities and differences. Lastly, a table summarizes the findings, were further insights could be drawn to help service companies be more aware of both their spending and ecological responsibility.
\end{abstract}

Keywords: ecodesign, digital services, design for x (DfX), design methods, ontological analysis

\section{Introduction}

As technology continues to evolve, more and more companies shift from traditional product markets to offering services to their customers (Bitner et al., 2008). Services are often designed with the maximum value in mind - a beneficial experience for the user, while making it profitable for the service provider (design-for-cost) (Xiaochuan, 2004; Xiaochuan et al., 2004). However, with the rise of environmental consciousness brought by evident effects of climate change, service industries have started looking into solutions that involve environmental impact, energy consumption, and carbon footprint as valid design considerations (design-for-environment) (van Hemel and Keldmann, 1996). This research aims to combine both financial cost and environmental impact (design-for-cost-andenvironment) in the same design plane which has not been properly documented for service design, specifically in the context of digital transformation.

Assessing the global environmental impact and financial cost of digital services can be a complex task. The variety of support systems (e.g. mobile 3G/ 4G, telephone lines, DSL, FTTH, etc.), and user terminals (e.g. laptop, desktop computer, smartphone, tablet, etc.) leads to high combination of factors to consider. Conventional assessment tools for product eco-design such as Life Cycle Assessment (LCA) (International Organisation for Standardization, n.d.) give precise results at the expense of time, resource inefficiency, and highly-skilled manpower (Malmodin et al., 2001; Scharnhorst, 2008; Stutz et al., 2003). Although LCA can be a great tool for assessing the environmental impact of products, it can be rather challenging to define the same boundaries for services given that services can be a combination of products, processes, sub-processes, or even other service systems (Sousa and Ometto, 2011). This can be explained by the complex nature brought by interconnected network equipment, and the difficulty to represent digital services. In addition, there has not been enough 
published works on LCA of digital services, only on energy efficiency (Yoro et al., 2018a, 2018b, 2017) and network optimization (Masoudi et al., 2019; Rocha et al., 2017).

Thus, a primary challenge to concurrently design for cost and environment is to adopt relevant representation tools and techniques for digital services. Describing the nature of the service in a more visual or graphical representation would allow us to better attribute and extract information regarding cost and environmental impact. More so, using a service representation as a use case description would serve as an input to facilitate the environmental impact assessment.

\section{Methodology}

The idea of using service representation approaches to facilitate design-for-cost-and-environment sprung from (Boughnim and Yannou, 2005). Their work investigated on the use of Service Blueprinting method in service engineering and designing Product-Service Systems (PSS). A use case on a service company presented a detailed service blueprint, highlighting its global cost and aggregated environmental impact throughout the described service life cycle. We continued to systematically look for similar approaches to model and visualize service and business processes. Searching through well-known research databases such as IEEE Xplore, Science Direct, Springer, and Research Gate, among others, we were able to find some promising service representation techniques and operations management tools.

For the context of this study, we have decided to choose the following approaches: Service Blueprinting, Process Chain Networks, Business Process Model \& Notation, and Customer Journey Mapping, as shown in Table 1. Other approaches were eliminated based on the criteria of being a version of the previously mentioned approaches (Al-Fedaghi, 2014), while others do not fit well with high-level service descriptions (e.g. UML, SysML, and Flowcharting) (Aagesen and Krogstie, 2015; Geambasu, 2012). The next section discusses these approaches in detail, followed by a comparison of elements, service overview, and mode of use.

Table 1. List of chosen service representation approaches

\begin{tabular}{|l|r|r|}
\hline \multicolumn{1}{|c|}{ Approach } & \multicolumn{1}{c|}{ Authors } & Financial Cost/ Environmental Impact \\
\hline Service Blueprinting & (Shostack, 1982, 1984) & (Boughnim and Yannou, 2005) \\
\hline Process Chain Network & (Sampson, 2012) & $\begin{array}{r}\text { (Bae and Kim, 2015; } \\
\text { Kazemzadeh et al., 2015a) }\end{array}$ \\
\hline $\begin{array}{l}\text { Business Process Model \& } \\
\text { Notation }\end{array}$ & $\begin{array}{r}\text { (Brocke et al., 2012; } \\
\text { (Geambasu, 2012; }\end{array}$ & $\begin{array}{r}\text { Recker et al., 2012; Seidel et al., 2012) } \\
\hline \text { Customer Journey Mapping }\end{array}$ \\
& $\begin{array}{r}\text { (Crosier and Handford, 2012; } \\
\text { Følstad and Kvale, 2018a) }\end{array}$ & --- \\
\hline
\end{tabular}

To further compare the similarities and differences of each approach, an ontological analysis can be utilized. The aim of this analysis is to compare the modelling formalisms of Service Blueprinting, which was chosen as the basis of formalism (concept A) to the other service representation approaches based on the "embodied ontology concept" (Wand and Weber, 2008) and the "conceptual span of terms theory" (Milton and Kazmierczak, 2004).

This method enables us to compare the core concepts of the modelling languages to find similarities and differences. Described below are the steps followed given this premise:

1. Determine the concepts of $A$ that are $\left\langle a_{1}\right\rangle,\left\langle a_{2}\right\rangle, \ldots,\left\langle a_{n}\right\rangle$.

2. Determine the concepts of $B$ that are $\left\langle b_{1}\right\rangle,\left\langle b_{2}\right\rangle, \ldots,\left\langle b_{n}\right\rangle$.

3. Perform a forward and backward evaluation of these concepts and tabulate the results. Concepts from A will be taken in comparison to concepts from B, using semiotics theoriesbased on signs, objects, and meanings.

4. Analyze, interpret, and discuss the results.

Thus, a minimal combination of concepts from B covering the maximum semantic field can be chosen. As a supportive concept $\left\langle\right.$ bi' $^{\prime}+\ldots+$ bj' $\rangle$ from B may provide full or partial coverage of semantic field to $<\mathrm{a} 1>$. We can represent this as,

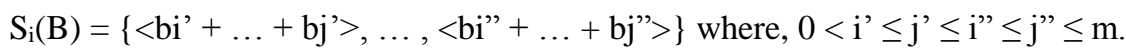


This equation describes how the semantic field $\left\langle a_{1}\right\rangle$ is covered by $\langle$ bi' $+\ldots+$ bj' $\rangle$, but also independently covered with in $\langle\mathrm{bi} "+\ldots+$ bj” $\rangle$. If there are no coverage from B on the semantic field for $\left\langle a_{1}\right\rangle$, then $S_{i}(B)=\{\varnothing\}$. Each of these categories, results can be indicated using symbols to easily convey the idea of the comparison in a tabular form as done by (Kazemzadeh et al., 2015b). The indicators shall be: full coverage $(\checkmark)$, partial coverage $(\checkmark$ p), and no coverage $(x)$, as shown below (Figure 1.)

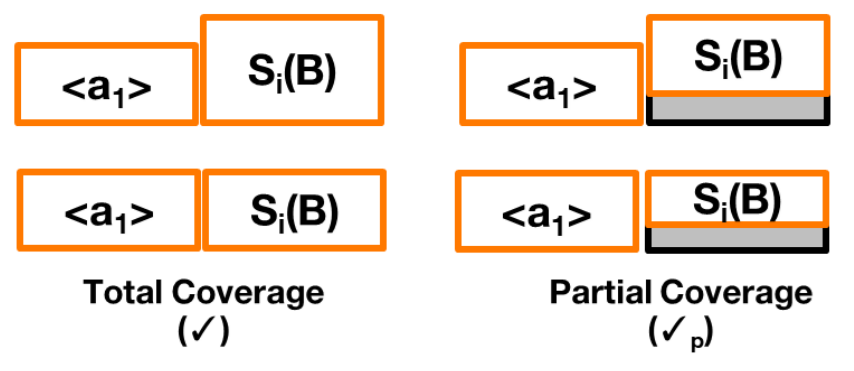

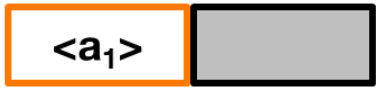

No Coverage

$(x)$

Figure 1. Degree of coverage in semantic field (Milton and Kazmierczak, 2004)

\section{Approaches}

Each of the four approaches will be briefly introduced to give a general overview of how these methods are used to visually represent a service, process, or sub-process. In addition, a list of key concepts and elements will be described and provided, which will then be used in the ontological analysis. Below (Figure 2) presents models of all four service representation approaches.

1

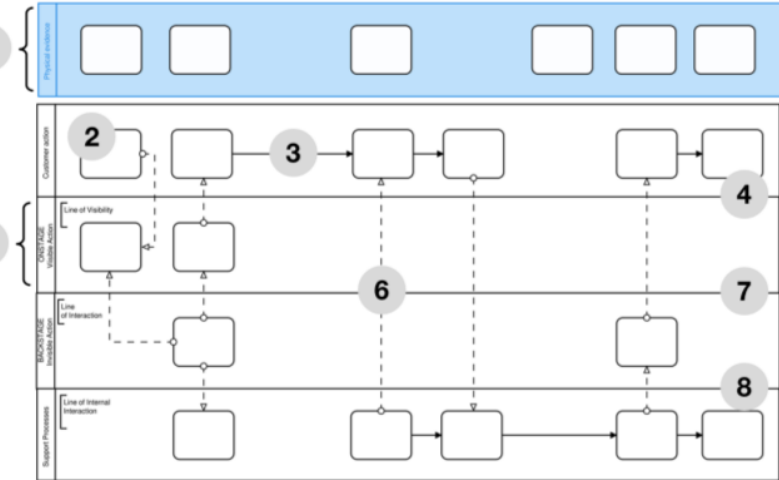

Service Blueprinting (SBP)
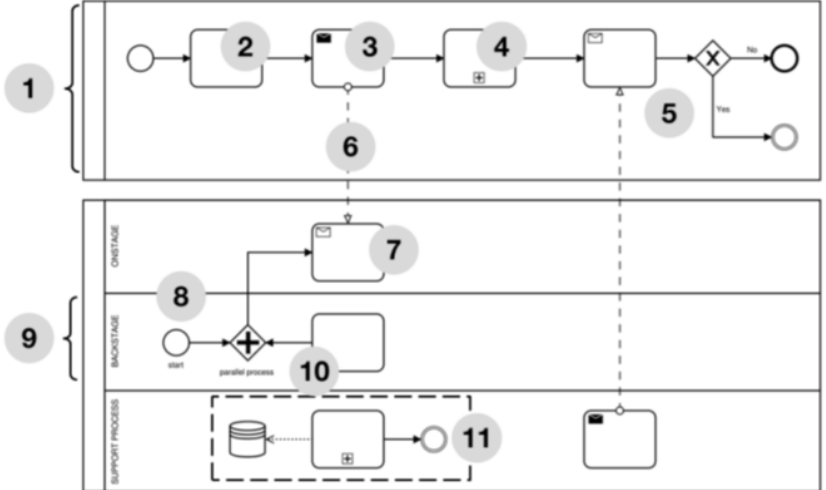

Business Process Model \& Notation (BPMN)

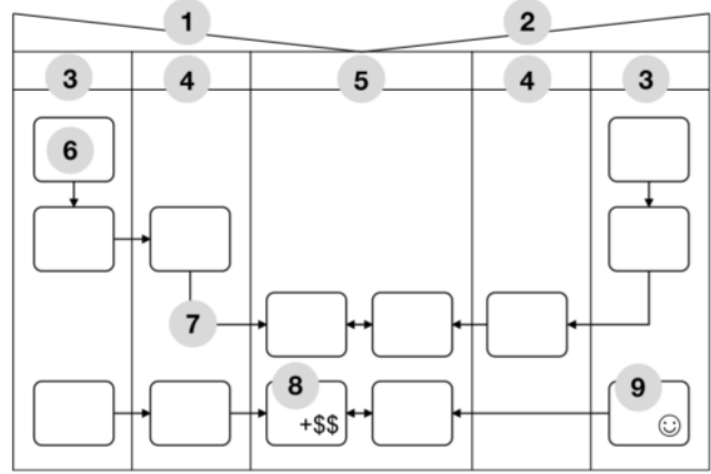

Process Chain Networks (PCN)
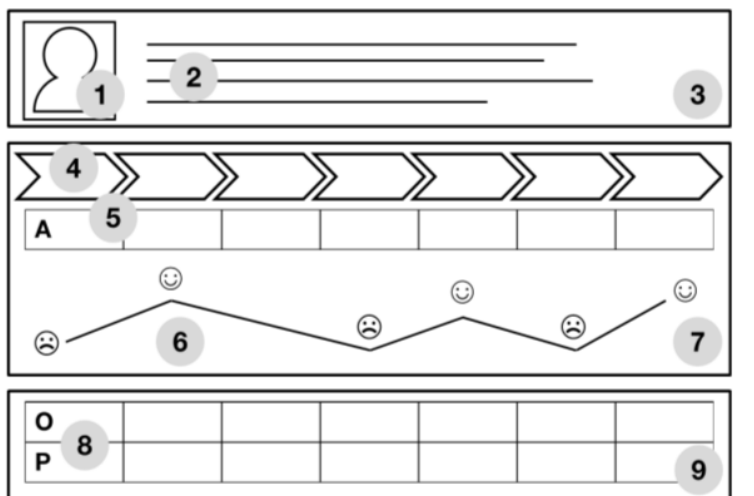

Customer Journey Mapping (CJM)

Figure 2. Service representation models, with numbered legends 


\subsection{Service Blueprinting}

Service Blueprinting was first described by (Shostack, 1982), originally to help visualize service processes in terms of physical evidences, and customer and employee actions through the different layers of interaction. This has now evolved as a marketing tool in improving service operations. Service Blueprinting involves four steps: the identification of all necessary processes, the isolation of fail points, the establishment of time frames, and a cost-benefit analysis (Shostack, 1984). However, the modern service blueprint is based on the customer view, and not the organizational perspective. This means that customer interactions with individuals or technologies are the main features of a service blueprint (Kazemzadeh et al., 2015b). This is in contrast to the traditional version where the way how providers deliver their service to the customer is at the heart of the analysis (Haugen, 2014).

Table 1 below lists the key concepts and elements involved in a traditional service blueprint as described by (Bitner et al., 2008). The numbered legends can be found in Figure 2. Aside from the elements (i.e. shapes, arrows, etc.), the lines that separates the different Actor Categories can give insights when analyzing an existing service or designing a new one based on certain considerations. Moreover, (Boughnim and Yannou, 2005) suggests that isolating each action flow, there is a possibility to analyses and measure the performance of each action in terms of cost and environmental impact, through activity-based costing and bottom-up life cycle analysis, respectively.

Table 2. Ontological concepts and elements of SBP

\begin{tabular}{|l|c|l|}
\hline \multicolumn{1}{|c|}{ Concepts } & Legend(s) & \multicolumn{1}{c|}{ Description } \\
\hline Action & 2 & $\begin{array}{l}\text { Actions by the customer, employees (both onstage and } \\
\text { backstage), support staff that builds an action flow or a process. }\end{array}$ \\
\hline Action Flow & 3 & Sequence of actions by an actor \\
\hline Communication Flow & 6 & $\begin{array}{l}\text { Flow of communication between any participants which usually } \\
\text { crosses one or more lines }\end{array}$ \\
\hline Actor Categories & 5 & $\begin{array}{l}\text { Customers, onstage employees, backstage employees, and support } \\
\text { staff }\end{array}$ \\
\hline Physical Evidence & 1 & $\begin{array}{l}\text { Tangible things that the customer sees during the service process } \\
\text { which influence their perception of the service quality }\end{array}$ \\
\hline Line of Interaction & 4 & $\begin{array}{l}\text { Interface between the customer and the frontline employees or } \\
\text { system (onstage) }\end{array}$ \\
\hline Line of Visibility & 7 & Interface between onstage and backstage employees or system \\
\hline Line of Internal Interaction & 8 & $\begin{array}{l}\text { Interface between back stage employees and support staff or } \\
\text { systems }\end{array}$ \\
\hline
\end{tabular}

\subsection{Process Chain Network}

Process Chain Network was introduced by (Sampson, 2012), which builds on the strength of other flowcharting techniques while emphasizing the unique conditions and design opportunities for interactive service processes. The aim for PCN is to illustrate the balance between the provider and the consumer by describing the dynamics of their actions and interactions. PCN is also known to have different modes depending on the needs of the service designer. These modes are based on the following operations management principles towards service innovation: process efficiency, economies of scale, and customization (Sampson, 2012). The primary concepts and elements of a PCN framework as described by (Sampson, 2012) are listed below (Table 3).

Aside from the different service operation modes that can be used with process chain networks, another interesting feature of PCN is the use of monetary and nonmonetary tags that can be attached in process entities. These serves to provide additional information that can be used to further analyze the service system. Tagging, both monetary and non-monetary, may not be provide direct information regarding environmental impact but it serves as a step towards evaluating the global cost of services by following the money flow in the different processes and sub-processes involved. 
Table 3. Ontological concepts and elements of PCN

\begin{tabular}{|l|c|l|}
\hline \multicolumn{1}{|c|}{ Concepts } & Legend(s) & \multicolumn{1}{c|}{ Description } \\
\hline Process Chain & 6 & Sequence of steps with an identifiable purpose \\
\hline Process Entity & 1,2 & Any entity that participates and makes decision about in a process chain \\
\hline Arrows & 7 & Represents state dependency and connects process steps \\
\hline Value & $6,7,8,9$ & Satisfaction of the needs of the process entity \\
\hline Specific beneficiary & 1 & An entity that participates in a process chain to have specific needs met \\
\hline Generic beneficiary & 2 & $\begin{array}{l}\text { An entity that participates in a process chain to acquire generic resources } \\
\text { (i.e. money), to meet needs from other process chains }\end{array}$ \\
\hline Process Domain & $3,4,5$ & Portion of the process chain that falls under an entity's responsibility \\
\hline Monetary Tag & 8 & Supplementary information that are tagged to represent flow of money \\
\hline Non-monetary Tag & 9 & Tags that represents indicators such as emotion, hunger, satisfaction, etc. \\
\hline Direct Interaction & 5 & Steps involving person to person interaction between entities \\
\hline Surrogate Interaction & 4 & Steps involving non-human resources or systems of another entity \\
\hline $\begin{array}{l}\text { Independent } \\
\text { Interaction }\end{array}$ & 3 & $\begin{array}{l}\text { Steps that are performed independently from other entities in the flow of } \\
\text { process chains }\end{array}$ \\
\hline
\end{tabular}

\subsection{Business Process Model \& Notation}

Business Process Model \& Notation has received attentions from both the industry and the academic community in the short period of time since it was released by the Business Process Management Initiative in 2005 (Recker, 2008). It has then been maintained and upgraded by the Object Management Group which released BPMN 2.0 in 2011 (Kazemzadeh et al., 2015c). The core concept set of BPMN is defined for business analysts and non-technical users, to depict business modelling activities that can be easily understood by all stakeholders. The extended concept set however, can be utilized by workflow engineers and service architects to draw more technical diagrams (Aagesen and Krogstie, 2015). A list of elements in the basic concept set is presented below (Table 4).

Table 4. Ontological concepts and elements of BPMN

\begin{tabular}{|l|c|l|}
\hline \multicolumn{1}{|c|}{ Concepts } & Legend(s) & \multicolumn{1}{c|}{ Description } \\
\hline Activity & 4 & $\begin{array}{l}\text { Work that an organization performs in a process, which can either be atomic } \\
\text { or compound }\end{array}$ \\
\hline Event & 8 & $\begin{array}{l}\text { Something that happens through the course of the process which can be in } \\
\text { the beginning (start event), during (intermediate) or in the end (end event) }\end{array}$ \\
\hline Pool & 1 & Represents a participant in the process \\
\hline Lane & 9 & Sub-partition of a pool to describe internal or external roles, for example \\
\hline Sequence Flow & 2 & Connects and orders activities within a pool \\
\hline Message Flow & 6 & Shows flow between two different pools in a diagram \\
\hline Message & 3 & Depicts the content of communication between participants \\
\hline Gateway & 5 & Determines traditional decisions: forking, merging or joining paths \\
\hline Text Annotation & 10 & Additional information provided for the BPMN diagram readers \\
\hline Group & 11 & Identifies logically related activities together \\
\hline
\end{tabular}

The BPMN modelling formality provides predefined sets of shapes and arrows that correspond to unique concepts and activities. This level of formality opens up opportunities for service designers to innovate and define a new set of elements that would complement the existing semantic dictionary. For instance, (Recker et al., 2012) came up with an concept extension to help include carbon footprints for processes using BPMN. The extension includes notations for fuel-consuming activities, paperconsuming activities, Green House Gas (GHG) flow arrows, and GHG emission indicators. Such modelling enables service designers to identify sources and main drivers of carbon emission alongside 
the value chain (Brocke et al., 2012). This information can then be used to assess and improve processes and activities to comply with specific environmental considerations.

\subsection{Customer Journey Mapping}

Customer Journey Mapping is an approach to analyse emotional responses of the customer to products, goods, and service (Crosier and Handford, 2012). The customer journey perspectives not only seen as a way to understand the customer's point of view, but also to gain insights into their experiences, or being able to emphasize with the customer (Følstad and Kvale, 2018a). Hence, CJM addresses implemented service processes, and encompasses data collection with customers and employees, data analysis both qualitative and quantitative, and presentation of results through visualization (Diana et al., 2009). Table 5 below descries the concepts and elements of CJM.

Table 5. Ontological concepts and elements of CJM

\begin{tabular}{|l|c|l|}
\hline \multicolumn{1}{|c|}{ Concepts } & Legend(s) & \multicolumn{1}{c|}{ Description } \\
\hline Zone A: The Lens & 3 & Part of the CJM which provides the descriptions and constraints \\
\hline Persona & 1 & Belongs to Zone A, describes the "who" of the journey \\
\hline Scenario & 2 & Belongs to Zone A, describes the specific scenario to be examined \\
\hline $\begin{array}{l}\text { Zone B: The } \\
\text { Experience }\end{array}$ & 7 & Part of the CJM where input from research is duly organized \\
\hline Phases & 4 & Belongs to Zone B, divides the customer journey into moments \\
\hline Actions \& Thoughts & 5 & Belongs to Zone B, considered as the heart of the visualized journey \\
\hline $\begin{array}{l}\text { Emotional } \\
\text { Experience }\end{array}$ & 6 & $\begin{array}{l}\text { Belongs to Zone B, visualizes the persona's emotions in different } \\
\text { phases }\end{array}$ \\
\hline Zone C: The Insights & 9 & Part of the CJM where feedback based on other parts are expressed \\
\hline $\begin{array}{l}\text { Opportunities } \\
\text { \& Problems }\end{array}$ & 8 & $\begin{array}{l}\text { Belongs to Zone C, presents the business goals and pain-points that } \\
\text { were discovered in the analysis }\end{array}$ \\
\hline
\end{tabular}

Customer journey mapping is typically seen as part of a more comprehensive design process. Usually, customer journey maps are used as inputs for redesigning or re-engineering existing services, however some practitioners have recently used the tool as a way to monitor service delivery (Følstad and Kvale, 2018b). However, CJM does not provide relevant information on financial cost and environmental impact but rather focuses on the customer journey of discovery, provisioning, and feedback. What customer journey mapping lacks in service eco-design aspects, it compensates with the value engineering perspective which is equally important in design-for-cost-and-environment. Enriching the experience of the customer greatly affects the quality of the service being delivered. Thus, customer journey mapping can be a valuable tool in creating the service representation diagrams from other previously mentioned approaches.

\section{Discussions}

To start, the ontological concepts and key elements were collected for each approach from Table 2, Table 3, Table 4, and Table 5. Service Blueprinting was used as concept A where the concepts of other approaches will be compared against. This was for two reasons: SBP was the initial approach where all other approach were related to, according to literature (Følstad and Kvale, 2018a; Kazemzadeh et al., 2015d, 2015e). In addition, (Boughnim and Yannou, 2005) suggests that SBP can present information on both financial cost and environmental impact, which we want to retain for an effective design-for-cost-and-environment. After applying the steps mentioned in the methodology, Table 6 below summarizes the qualitative assessment of similarities and differences, presented in through the different levels of semantic coverage (refer to Figure 1).

Based on the premise discussed in Equation (1), we know that if $\left\langle\right.$ bi' $^{\prime}+\ldots+$ bj' $\rangle$ fully covers

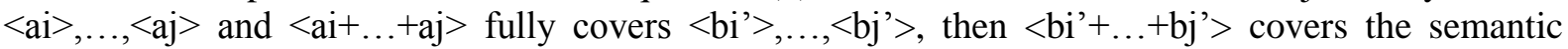
field as $<a i+\ldots+a j>$ by association (Kazemzadeh et al., 2015b). Using the described methodology for the comparison of SBP and PCN, Table 6 shows the SBP elements such as Action, Action Flow, and Communication Flow are fully covered in PCN, while Actor Categories, Physical Evidence, and Line 
of Interaction are only partially covered. The comparison suggests that SBP and PCN categorize the Actions and Process Steps concepts in fundamentally different ways. On one hand, SBP highlights how customers behaves with a provider (Line of Interaction); categorizes the provider's actions based on visibility (Line of Visibility); and whether the action is performed by contact employees in contract to support staff (Line of Internal Interaction) (Kazemzadeh et al., 2015b). PCN, on the other hand, discriminates actions whether they are done autonomously (Process Domain + Independent Processing), action as a result of another customer-induced action (Process Domain + Surrogate Interaction), or a direct interaction between the entities (Process Domain + Direct Interaction).

Table 6. Summary of qualitative assessments for ontological analysis

\begin{tabular}{|c|c|c|c|c|c|c|}
\hline SBP & \multicolumn{2}{|r|}{$\mathrm{PCN}$} & \multicolumn{2}{|r|}{ CJM } & \multicolumn{2}{|r|}{ BPMN } \\
\hline Action & $\checkmark$ & Process Steps & $\checkmark$ & Actions \& Thoughts & $\checkmark$ & Activity \\
\hline Action Flow & $\checkmark$ & Arrows & $\checkmark \mathrm{p}$ & Phases & $\checkmark$ & $\begin{array}{l}\text { Sequence Flow + } \\
\text { Message Flow }\end{array}$ \\
\hline Communication Flow & $\checkmark$ & Arrows & $x$ & - & $\checkmark$ & $\begin{array}{l}\text { Sequence Flow + } \\
\text { Message Flow }\end{array}$ \\
\hline Actor Categories & $\checkmark \mathrm{p}$ & $\begin{array}{l}\text { Process Entity + } \\
\text { Process Domain }\end{array}$ & $\checkmark p$ & $\begin{array}{l}\text { Zone A: The Lens + } \\
\text { Zone C. The Insights }\end{array}$ & $\checkmark$ & Pool + Lanes \\
\hline Physical Evidence & $\checkmark p$ & Value & $\checkmark$ & $\begin{array}{l}\text { Zone B: The } \\
\text { Experience }\end{array}$ & $x$ & - \\
\hline Line of Interaction & $\checkmark p$ & $\begin{array}{l}\text { Direct Interaction } \\
+ \text { Process Entity }\end{array}$ & $\times$ & - & $\checkmark$ & Pool + Lanes \\
\hline Line of Visibility & $x$ & - & $\checkmark \mathrm{p}$ & Zone A: The Lens & $\checkmark$ & Pool + Lanes \\
\hline $\begin{array}{l}\text { Line of Internal } \\
\text { Interaction }\end{array}$ & $x$ & - & $x$ & - & $\checkmark$ & Pool + Lanes \\
\hline
\end{tabular}

As for the comparison between SBP and CJM, Actions and Physical Evidence are fully covered in CJM by Actions \& Thoughts, and Zone B: The Experience, respectively. The ones partial coverage include Action Flow with Phases; Line of Visibility with Zone A: The Lens; and Actor Categories with Zone A: The Lens + Zone C: The Insights. Other than those already mentioned there is no coverage for the remaining elements. This forms a rather weak connection and translatability for SBP and CJM. Alternatively, the customer journey that serves as a valuable input in building a service blueprint, as previously discussed. Lastly, for the comparison between SBP and BPMN, it can be deduced from the qualitative assessment that BPMN does not provide concepts regarding customer experience. While SBP highlights this using Physical Evidence, BPMN lacks any similar concept. Then, we can say that a BPMN diagram presents less customer specific perspective, compared to SBP. As for the most part, BPMN covers all the other concepts in Service Blueprinting that represents the core of the service systems and processes. Hence, this makes service blueprints highly compatible and translatable into BPMN diagrams, but the converse does not apply in terms of semantic elements for BPMN diagrams to service blueprints.

There is a presumption that SBP can be the most viable option for service representation thus, choosing it as the basis of formalism (concept A). Through the ontological analysis, we were able to observe that there are significant elements not present in SBP that can be helpful for obtaining and extracting information regarding financial cost and environmental impact for design-for-cost-andenvironment. For example, these are monetary and non-monetary tags from PCN, and text annotations and extended actions from BPMN which are not directly covered by SBP. The challenge now is to looks for new ways to adapt these useful elements to enrich and enhance the existing capabilities of the previously mentioned service representation approaches to better allocate both financial cost and environmental impact for each activity block.

\section{Conclusion}

As a response to the challenges of investigating on new approaches to evaluate financial cost and environmental impact towards design-for-cost-and-environment, this paper presented four different 
service representation approaches and operations management tools. Service Blueprinting (SBP) highlights how providers deliver their service to the customer through the different service layer dynamics, and supported by Physical Evidences. Process Chain Network (PCN) describes the chain of activities in a process and how the entities (i.e. customer and provider) interact with each other. Business Process Model \& Notation (BPMN) provides a formal modelling language that service designers can use to represent processes and activities in different degrees of the service. Lastly, Customer Journey Mapping (CJM) follows the experience of the customer throughout a specific scenario, complement with the emotion experience, actions and thoughts.

Each of these approaches were presented, concepts and elements listed accordingly, and analyzed given the context of cost and environmental impact. In addition, an ontologically analysis was conducted to further compare the similarities and differences of each of the approaches on a semantic level. A summary table was presented, as a culmination of these insights (Table 6). Results from these comparisons suggest that SBP and BPMN have the most coverage among the four approaches. This means that concepts and elements from SBP and BPMN are easily transferrable and translatable, especially on the basis of both financial cost and environmental impact. Moreover, the monetary and non-monetary tagging features in PCN can be sued to explore related information for each Action and Process Entity. In addition, the ability to supplement the standard BPMN with extended notations opens the opportunity to further integrate other elements for context-specific considerations, such as the carbon footprint indicators presented by (Recker et al., 2012). Customer Journey Mapping might not be able to provide the specific information; CJM still serves as a helpful tool in building the diagrams for all the other approaches.

These findings can be helpful to service companies in being more aware of both their spending and ecological responsibility. Two scenarios were envisioned by the authors for the further use of these findings. First, from an industrial perspective, the service representation diagram can be high-level description to facilitate the assessment of an existing service with regards to financial cost (i.e. global costing or activity-based costing), and environmental impact throughout the service life cycle (i.e. raw material extraction, manufacturing, transportation, use phase, end-of-life). To facilitate a complete assessment, other necessary information and technical representation should also be provided. And for the second case, it can also be integrated in a company's design process and time-to-market protocols in the eco-design of new services towards design-for-cost-and-the-environment.

\section{Acknowledgement}

The authors would like to thank Orange Labs for their generous support, and for providing the use case (Orange digital services) for the verification of the proposed modelling approach, as the industrial partner. We would also like to extend our gratitude to Université Paris-Saclay, CentraleSupélec, Laboratoire Génie Industriel, for providing the necessary academic background in the pursuit of this research topic. AM+DG.

\section{References}

Aagesen, G. and Krogstie, J. (2015), "BPMN 2.0 for Modeling Business Processes”, In: vom Brocke, J. and Rosemann, M. (Eds.), Handbook on Business Process Management 1, Springer Berlin Heidelberg, Berlin, Heidelberg, pp. 219-250. https://doi.org/10.1007/978-3-642-45100-3_10

Al-Fedaghi, S. (2014), "Systems Design: SysML vs. Flowthing Modeling”, IJSEIA, Vol. 8, pp. 355-370. https://doi.org/10.14257/ijseia.2014.8.1.31

Bae, K.M. and Kim, Y.S. (2015), "Visualizing Service by Service Design Tools and PCN", IJUNESST, Vol. 8, pp. 83-90. https://doi.org/10.14257/ijunesst.2015.8.9.10

Bitner, M.J., Ostrom, A.L. and Morgan, F.N. (2008), "Service Blueprinting: A Practical Technique for Service Innovation”, California Management Review, Vol. 50, pp. 66-94. https://doi.org/10.2307/41166446

Boughnim, N. and Yannou, B. (2005), "Using Blueprinting Method For Developing Product-Service Systems", ICED, Vol. 17.

Brocke, J., vom Seidel, S. and Recker, J. (2012), Green business process management: towards the sustainable enterprise, Progress in IS, Springer, Heidelberg, New York.

Crosier, A. and Handford, A. (2012), "Customer Journey Mapping as an Advocacy Tool for Disabled People: A Case Study”, Social Marketing Quarterly, Vol. 18, pp. 67-76. https://doi.org/10.1177/1524500411435483

Diana, C., Pacenti, E. and Tassi, R. (2009), "Visualtiles: Communication tools for (service) design, in: Service Design 2009. Presented at the DeThinking Service/ ReThinking Design, Oslo”, Norway, pp. 65-76. 
Følstad, A. and Kvale, K. (2018a), "Customer journeys: a systematic literature review”, Journal of Service Theory and Practice, Vol. 28. https://doi.org/10.1108/JSTP-11-2014-0261

Følstad, A. and Kvale, K. (2018b), "Customer journeys: a systematic literature review", Journal of Service Theory and Practice, Vol. 28, pp. 196-227. https://doi.org/10.1108/JSTP-11-2014-0261

Geambasu, C.V. (2012), "BPMN vs. UML Activity Diagram for Business Process Modeling”, Accounting and Management Information Systems, Vol. 11, p. 15.

Haugen, M. (2014), Service Blueprints: Persistent qualities and future potential. Norwegian University of Science and Technology 15.

International Organisation for Standardization. (n.d), ISO 14040:2006 [WWW Document]. URL https://www.iso.org/cms/render/live/en/sites/isoorg/contents/data/standard/03/74/37456.html (accessed 2.5.20).

Kazemzadeh, Y., Milton, S. and Johnson, L. (2015a), "Process Chain Network (PCN) and Business Process Modeling Notation (BPMN): A Comparison of Concepts", Journal of Management and Strategy, Vol. 6. https://doi.org/10.5430/jms.v6n1p88

Kazemzadeh, Y., Milton, S. and Johnson, L. (2015b), "Service blueprinting and process-chain-network: an ontological comparison", International Journal of Qualitative Research in Services, Vol. 2. https://doi.org/ 10.1504/IJQRS.2015.069775

Kazemzadeh, Y., Milton, S. and Johnson, L. (2015c), “An Explication of Three Service Business Process Modeling Approaches", Australian Journal of Business and Economic Studies, Vol. 1.

Kazemzadeh, Y., Milton, S.K. and Johnson, L.W. (2015d), "A Comparison of Concepts in Service Blueprinting and Process Chain Network (PCN)", International Journal of Business and Management, Vol. 10. https://doi.org/10.5539/ijbm.v10n4p13

Kazemzadeh, Y., Milton, S.K. and Johnson, L.W. (2015e), “A Conceptual Comparison of Service Blueprinting and Business Process Modeling Notation (BPMN)", Asian Social Science, Vol. 11. https://doi.org/ 10.5539/ass.v11n12p307

Malmodin, J., Oliv, L., Bergmark, P. (2001), "Life cycle assessment of third generation (3G) wireless telecommunication systems at Ericsson", Presented at the Proceedings Second International Symposium on Environmentally Conscious Design and Inverse Manufacturing, pp. 328-334. https://doi.org/ 10.1109/ECODIM.2001.992375

Masoudi, M. et al. (2019), “Green Mobile Networks for 5G and Beyond”, IEEE Access, Vol. 7, pp. 107270107299. https://doi.org/10.1109/ACCESS.2019.2932777

Milton, S. and Kazmierczak, E. (2004), “An Ontology of Data Modeling Languages: A Study Using a CommonSense Realistic Ontology”, J. Database Manag, Vol. 15, pp. 19-38. https://doi.org/10.4018/jdm.2004040102

Recker, J. (2008), BPMN Modeling - Who, Where, How and Why. BPTrends 5.

Recker, J. et al. (2012), "Modeling and Analyzing the Carbon Footprint of Business Processes", Green Business Process Management, pp. 93-109. https://doi.org/10.1007/978-3-642-27488-6_6

Rocha, H. et al. (2017), "SooGREEN: Service-oriented optimization of green mobile networks", Presented at the 2017 15th International Symposium on Modeling and Optimization in Mobile, Ad Hoc, and Wireless Networks (WiOpt), pp. 1-8. https://doi.org/10.23919/WIOPT.2017.7959935

Sampson, S. (2012), "Visualizing Service Operations”, Journal of Service Research, Vol. 15, pp. 182-198. https://doi.org/10.1177/1094670511435541

Scharnhorst, W. (2008), "Life cycle assessment in the telecommunication industry: A review", Int J Life Cycle Assess, Vol. 13, pp. 75-86. https://doi.org/10.1065/lca2006.11.285

Seidel, S., Recker, J. and Brocke, J.V. (2012), "Green Business Process Management”, Green Business Process Management, pp. 3-13. https://doi.org/10.1007/978-3-642-27488-6_1

Shostack, G.L. (1984), "Designing Services That Deliver”, Harvard Business Review, No. 84115, p. 8.

Shostack, G.L. (1982), "How to Design a Service", European Journal of Marketing, Vol. 16, pp. 49-63. https://doi.org/10.1108/EUM0000000004799

Sousa, S.R. and Ometto, A.R. (2011), “Application of life cycle assessment in service industries: a review”, Life Cycle Management, Vol. 9.

Stutz, M. et al. (2003), "Life cycle assessment of the mobile communication system UMTS: Towards ecoefficient systems", Presented at the IEEE International Symposium on Electronics and the Environment, 2003, pp. 141-146. https://doi.org/10.1109/ISEE.2003.1208063

van Hemel, C.G. and Keldmann, T. (1996), "Applying "Design for X" Experience in Design for Environment", In: Huang, G.Q. (Ed.), Design for X, Springer Netherlands, Dordrecht, pp. 72-95. https://doi.org/10. 1007/978-94-011-3985-4_4

Wand, Y. and Weber, R. (2008), "On the ontological expressiveness of information systems analysis and design grammars”, Information Systems Journal, Vol. 3, pp. 217-237. https://doi.org/10.1111/j.1365-2575. 1993.tb00127.x 
Xiaochuan, C. (2004), "The Relationship between Design For Environment (DFE) and Design For Cost (DFC)", World Engineers' Convention, Vol. 4.

Xiaochuan, C. et al. (2004), "Methodology and technology of design for cost (DFC)", Presented at the Fifth World Congress on Intelligent Control and Automation, IEEE, Hangzhou, China, pp. 2834-2840. https://doi.org/10.1109/WCICA.2004.1342117

Yoro, W. et al. (2018a), "Energy Efficiency of a Network Equipment Per Service Category", Presented at the 2018 IEEE International Conference on Communications (ICC), pp. 1-6. https://doi.org/10.1109/ICC. 2018.8422369

Yoro, W. et al. (2018b), "Sharing the Network End-to-End Energy Consumption among Service Categories", Presented at the 2018 IEEE 87th Vehicular Technology Conference (VTC Spring), pp. 1-7. https://doi.org/10.1109/VTCSpring.2018.8417651

Yoro, W. et al. (2017), "Energy efficiency of a network per service", Presented at the 2017 15th International Symposium on Modeling and Optimization in Mobile, Ad Hoc, and Wireless Networks (WiOpt), pp. 1-5. https://doi.org/10.23919/WIOPT.2017.7959934 